\title{
Prevalence and correlates of hypertension in a semi-rural population of Southern India
}

\author{
Mandeep Singh $^{1} \cdot$ Atul Kotwal $^{2} \cdot{\text { Chetan } \mathrm{Mittal}^{1} \cdot \text { S. Ram Babu }}^{1} \cdot$ Sahul Bharti $^{3} \cdot$ C. Venkata S. Ram ${ }^{4}$
}

Received: 2 May 2017 / Revised: 6 September 2017 / Accepted: 7 September 2017 / Published online: 27 November 2017

(C) The Author(s) 2018. This article is published with open access

\begin{abstract}
While elevated blood pressure is a recognized risk factor for cardiovascular disease, the prevalence of hypertension still remains unclear for most populations. A door-to-door survey was conducted using modified WHO STEPS questionnaire in a group of villages under the Thavanampalle Mandal of Chittoor District in the state of Andhra Pradesh of South India. Data were collated and analyzed for 16,636 individuals (62.3\% females and $37.7 \%$ males) above 15 years of age. Overall, prevalence of hypertension (as per JNC-7 classification) was found to be $27.0 \%$ (95\% CI, 26.3, 27.7) in the surveyed community with $56.7 \%$ of the total hypertensives being diagnosed for the first time during the survey. An additional $39.1 \%$ had their blood pressure readings in the prehypertensive range. Among the known Hypertensives on treatment only $46.2 \%$ had a blood pressure recording within acceptable limits, with $31.2 \%$ in the prehypertensive range and only $15.0 \%$ in the normal range. Systolic blood pressure (SBP) of the surveyed population showed a continuous linear increase with age, but diastolic blood pressure (DBP) peaked and started reducing in early fifth decade in males. Male gender, increasing age, higher body mass index (BMI), increased waist-hip ratio, increased body weight, family history of hypertension, death of spouse, and diabetes were found to be positively correlated with hypertension. Risk factors of alcohol intake, use of ground nut/palm oil, and family history of diabetes lost their independent predictive ability for hypertension on multivariate logistic regression analysis. The level of physical activity was also not found to be a significant predictor of hypertension in the study population.
\end{abstract}

\section{Introduction}

Developing countries are known to have a high prevalence of hypertension and the suffering is aggravated by resource constraints and lack of awareness leading to poor control [1]. These issues are equally important and significant in India [2] where temporal trends of rising prevalence of hypertension have been documented [3]. From an analysis reported in 2005, 20.6\% of Indian men and 20.9\% of Indian women were suffering from hypertension in India and the prevalence rates were projected to increase to $22.9 \%$ and $23.6 \%$, respectively, by 2025 [4]. These projections are considered underestimates of the true prevalence which has

Chetan Mittal

cmittal@gmail.com

1 Total Health Foundation, Chittoor, Andhra Pradesh, India

2 ACMS, New Delhi, India

3 Build Healthy India Movement (BHIM), Chandigarh, India

4 Apollo Hospitals, Hyderabad, Telengana, India prompted the World Hypertension League to emphasize the need for local and regional surveillance of hypertension prevalence and associated risks [5]. Even though India follows standards like JNC-7 classification for hypertension, the population characteristics of change in blood pressure with age have not been documented well. Ever since the initiation of debate on J-curve for control of hypertension in coronary artery disease [6], diastolic pressure has gained attention especially the fall after 60 years of age [7]. Similar curves for Indian population have not been studied widely, without which, appropriate hypertension control strategies cannot be postulated to avoid overzealous control, especially in elderly.

In India, increasing prevalence of obesity has been primarily correlated with hypertension [8]. Other important reported risk factors include age, smoking, and chewing tobacco, alcohol consumption, raised BMI, consumption of low vegetables/fruits, high consumption of dietary fat and salt, and a sedentary lifestyle [9]. Even though there is a widely accepted belief that illiteracy is associated with higher prevalence of hypertension, literature from middleincome countries are not very conclusive. However, it has 
Table 1 Socio-demographic characteristics of the surveyed population

\begin{tabular}{|c|c|c|c|}
\hline Variables & Normal $^{\mathrm{a}}$ & Hypertensives & Total \\
\hline $\begin{array}{l}\text { Total population } \\
\text { (>15 years) }\end{array}$ & $\begin{array}{l}12,142 \\
(82.7 \%)\end{array}$ & $4494(17.3 \%)$ & $16,636(100 \%)$ \\
\hline Mean age in years & $\begin{array}{l}42.75 \\
\text { (CI } 42.5-44.1)\end{array}$ & $\begin{array}{l}56.21 \\
\text { (CI 55.7-56.7) }\end{array}$ & $\begin{array}{l}45.66 \\
(45.4-45.9)\end{array}$ \\
\hline \multicolumn{4}{|l|}{ Gender } \\
\hline Females & $8370(80.8 \%)$ & $1990(20.2 \%)$ & $10,360(37.7 \%)$ \\
\hline Males & $4672(74.4 \%)$ & $1604(25.6 \%)$ & $6276(62.3 \%)$ \\
\hline \multicolumn{4}{|l|}{ Educational status } \\
\hline Illiterates & $4280(70.7 \%)$ & $1774(29.3 \%)$ & $6054(36.4 \%)$ \\
\hline $\begin{array}{l}\text { Primary-middle } \\
\text { school }\end{array}$ & $4895(71.8 \%)$ & $1918(28.2 \%)$ & $6813(41.0 \%)$ \\
\hline ITI/Sr Sec & $1595(81.2 \%)$ & $370(18.8 \%)$ & $1965(11.8 \%)$ \\
\hline $\begin{array}{l}\text { Graduate and } \\
\text { above }\end{array}$ & $1372(76.1 \%)$ & $432(23.9 \%)$ & $1804(10.8 \%)$ \\
\hline \multicolumn{4}{|l|}{ Marital status } \\
\hline Married & $9917(78.3 \%)$ & $2754(21.7 \%)$ & $12,671(76.2 \%)$ \\
\hline Sep/Divorced & $73(73.7 \%)$ & $26(26.3 \%)$ & $99(0.6 \%)$ \\
\hline Unmarried & $1871(91.1 \%)$ & $182(8.9 \%)$ & $2053(12.3 \%)$ \\
\hline Widow(er) & $1181(65.1 \%)$ & $632(34.9 \%)$ & $1813(10.9 \%)$ \\
\hline \multicolumn{4}{|l|}{ Occupational status } \\
\hline $\begin{array}{l}\text { Employees/ } \\
\text { Shopkeeper }\end{array}$ & $588(75.5 \%)$ & $191(24.5 \%)$ & $779(4.7 \%)$ \\
\hline Farmers & $2388(74.4 \%)$ & $822(25.6 \%)$ & $3210(19.3 \%)$ \\
\hline Homemakers & $6247(80.3 \%)$ & $1532(19.7 \%)$ & $7779(46.8 \%)$ \\
\hline Semiskilled & $1007(76.6 \%)$ & $307(23.4 \%)$ & $1314(7.9 \%)$ \\
\hline Unemployed & $2812(79.1 \%)$ & $742(20.9 \%)$ & $3554(21.4 \%)$ \\
\hline \multicolumn{4}{|l|}{ Income (Rs) } \\
\hline$>11,400$ & $283(70.9 \%)$ & $116(29.1 \%)$ & $399(2.4 \%)$ \\
\hline $7600-11,400$ & $223(69.0 \%)$ & $100(31.0 \%)$ & $323(1.9 \%)$ \\
\hline $4500-7600$ & $861(72.6 \%)$ & $325(27.4 \%)$ & $1186(7.1 \%)$ \\
\hline $1500-4500$ & $2089(78.2 \%)$ & $583(21.8 \%)$ & $2672(16.1 \%)$ \\
\hline$<1500$ & $9586(79.5 \%)$ & $2470(20.5 \%)$ & $12,056(72.5 \%)$ \\
\hline
\end{tabular}

${ }^{\text {a Includes prehypertensives }}$

been well documented that control of hypertension is poor among uneducated, especially because literacy is a necessary skill for successful medication adherence and disease self-management [10]. In a study among rural population in 1994 it was shown that there was an inverse relationship between education level of individuals and hypertension [11]. On the contrary, educational status was not shown to be associated with a significant effect among Indian urban middle-class population [12]. Further, consanguinity has been noted to influence prevalence of hypertension [13]. South Asia and especially some parts of Southern India are reported to have high prevalence of consanguineous unions [14]. The current demographic and epidemiological survey was conducted to provide baseline information on the community for establishing a cohort. This paper provides results on estimate of baseline prevalence and risk factors of hypertension among the study participants, with an overall aim of providing information critical for the development and implementation of interventions and control strategies specific to a population [15].

\section{Material and methods}

A door-to-door community based cross-sectional survey was conducted using modified WHO STEPS questionnaire in a group of villages under the Thavanampalle Mandalone of the 66 Mandals in Chittoor District in the South Indian state of Andhra Pradesh; covered under "Total Health", a Corporate Social Responsibility (CSR) arm of Apollo Hospitals Enterprises Ltd. The study was approved by Apollo Health Education and Research Foundation (AHERF), Apollo Hospitals, Jubilee Hills, Hyderabad. Informed consent was obtained from all subjects in a language that they understood (Telugu/Kannadiga) and their signature/thumb imprint obtained.

As per 2011 census, Thavanampalle Mandal comprises 32 Gram Panchayats and 195 villages with a total population of 53,708 (49.7\% males and 50.3\% females). Out of 195 villages, 98 were selected for survey in phase 1, by stratified random sampling with a total population of 27,483 and family size of 4.04 as per the census of 2011. Of these, $22,303(81.3 \%)$ individuals were surveyed by making repeated visits to the households.

Data were collated and analyzed for 16,636 individuals (62.3\% females and $37.7 \%$ males) above 15 years of age from 8947 families with an average number of $1.86 \mathrm{mem}$ bers from each family (median 2). Trained healthcare workers keyed in the data in android tablets using application software specifically developed for this survey. Three consecutive recordings were made for every blood pressure measurement and an average of these three values was used for the data analysis. Hypertension was classified as per JNC -7 i.e.,: Normal-systolic blood pressure (SBP) $<120$ and diastolic blood pressure (DBP) $<80$; Prehypertensive SBP $120-139$ or DBP 80-89; Stage 1- SBP 140-159 or DBP 90-99; Stage 2- SBP 160-179/DBP 100-109; Stage 3- $\mathrm{SBP}>180 / \mathrm{DBP}>110$. Quality assurance measures included training of data collectors, supervision of a proportion of visits and measurements by researchers and periodic calibration of blood pressure (BP) instruments. Also, a sub sample of 3660 individuals in the overall surveyed population was contacted for ascertaining prevalence of consanguinity among them and among their parents. A database was created in MySQL and analyzed using iStata and SPSS 16. Kolmogorov-Smirnov test was used as test of normality. Statistical analysis of independent categorical variables with dependent continuous data was done using 
tests like $t$-test, analysis of variance (ANOVA) and correlation coefficient. Univariate and multivariate regression models were utilized for risk factor analysis. Further details of model have been provided in results section.

\section{Results}

The population comprised mainly of Hindus (95.2\%), 2.9\% Muslims; $1.8 \%$ Christians; and less than $0.1 \%$ Jains among other religions. They mostly belonged to backward (33\%) and schedule castes (32.6\%); with $72.5 \%$ having an income less than Rs. 1500 per head; $36.4 \%$ had no formal education; and were mainly farmers by profession. The sociodemographic profile of the studied population is tabulated in Table 1.

Mean $( \pm$ SD) SBP of the population was found to be 124 $( \pm 20) \mathrm{mm}$ of $\mathrm{Hg}$ and mean $( \pm$ SD) DBP was $77( \pm 12) \mathrm{mm}$ of Hg. The mean $( \pm \mathrm{SD}) \mathrm{SBP}$ among males and females was found to be $127( \pm 19) \mathrm{mm}$ of $\mathrm{Hg}$ and $122( \pm 20) \mathrm{mm}$ of $\mathrm{Hg}$, respectively, and mean $( \pm \mathrm{SD}) \mathrm{DBP}$ was found to be 79 $( \pm 12) \mathrm{mm}$ of $\mathrm{Hg}$ and $77( \pm 12) \mathrm{mm}$ of $\mathrm{Hg}$, respectively. Box and Whisker plot for distribution of systolic and DBP in both genders is shown in Fig. 1. This difference in blood

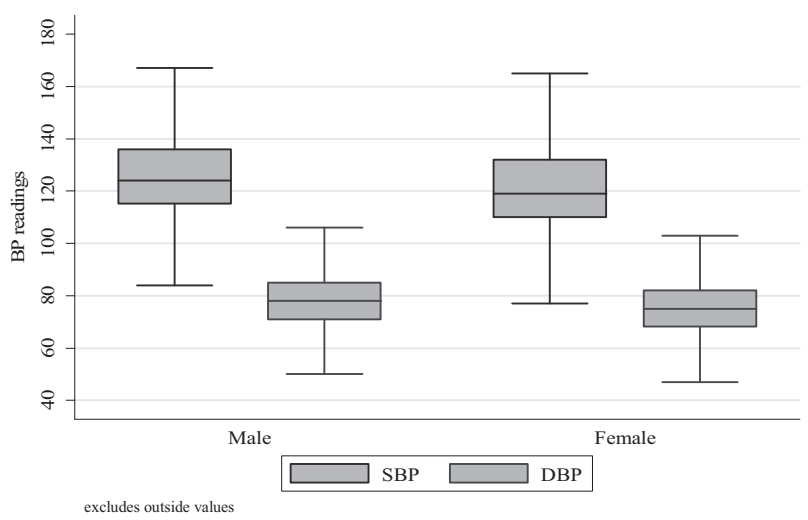

Fig. 1 Distribution of systolic blood pressure (SBP) and diastolic blood pressure (DBP) among males and females in study population pressure levels was found to be statistically significant with males having higher SBP $(p<0.001)$ and DBP levels $(p<$ 0.001). However, the difference of SBP and DBP measurements among males and females obliterated with age (Fig. 2). Interestingly, the DBP among males started falling after 45 years of age. This fall in DBP was 15 years earlier than reported in Western population [7].

The prevalence of Hypertension in the study population is shown in Table 2. Overall, 4494 individuals were identified as hypertensive (among them 2546 were identified for the first time, i.e., new hypertensives; and those diagnosed/ informed in the past as hypertensive were 1948), with prevalence of hypertension as $27.0 \%$ (95\% CI, 26.3\%, $27.7 \%$ ) in the surveyed community. A substantially large proportion of the population was unaware of their prehypertensive $(40.2 \%)$ or hypertensive $(17.3 \%)$ status prior to this survey. Less than half $(46.2 \%)$ of the known hypertensives (on some kind of therapy/management) had their blood pressure in non-hypertensive range; $14.6 \%$ had Stage 1 hypertension; 5.0\% had Stage 2 hypertension and $2.0 \%$ had Stage 3 hypertension (Table 2 and Fig. 3).

Age-adjusted (as per WHO standard population) genderwise prevalence of Hypertension is shown in Fig. 4. Percentage of prehypertensives and hypertensives was higher in males as compared to the females $(p<0.000)$.

Mean age was calculated for various stages of hypertension among male and female hypertensives. The mean was linearly correlated with raise in blood pressure levels from normotensives to stage 3 hypertensives as shown in Table 3. In both males and females mean age differed significantly among various hypertension categories on ANOVA testing $(F=132.8 ; \quad p$-value $=<0.0001$ and $F=527.2 ; \quad p$-value $=<0.0001$, respectively). Odds of hypertension ( $\mathrm{BP} \geq 140 / 90)$ were 1.44 times higher in males as compared to females and it was statistically significant (OR 1.44; 95\% CI: 1.34-1.56, $p$-value < 0.001).

The prevalence of hypertension is shown in Fig. 5. It is seen to increase linearly with increasing age. Whereas, $66.2 \%$ of the population under 25 years of age had blood pressure measurements within normal range; only $23.6 \%$ of
Fig. 2 Change in SBP and DBP with age among males and females

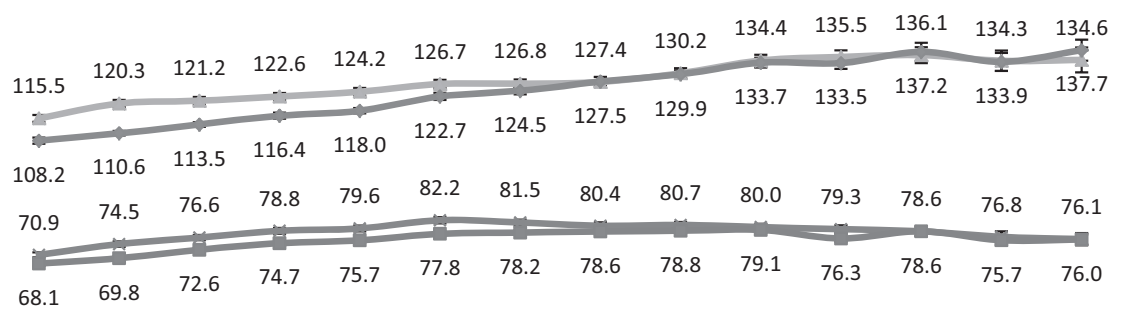

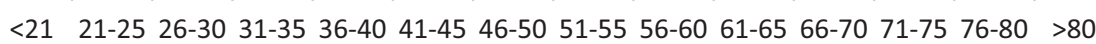
Female SBP $\simeq$ Male DBP $\because$ Female DBP 
Table 2 Prevalence of hypertension in study population

\begin{tabular}{llll}
\hline Grade of Hypertension (JNC-1) & Never informed/diagnosed earlier & Informed/diagnosed in the past & Total \\
\hline Normal & $6241(42.5 \%)$ & $292(15.0 \%)$ & $6533(39.3 \%)$ \\
PreHTN & $5901(40.2 \%)$ & $608(31.2 \%)$ & $6509(39.1 \%)$ \\
Stage 1 & $1834(12.5 \%)$ & 56.2 & $2428(14.6 \%)$ \\
Stage 2 & $532(3.6 \%)$ & $301(15.5 \%)$ & $833(5.0 \%)$ \\
Stage 3 & 2546 & $153(7.9 \%)$ & $333(2.0 \%)$ \\
Total & $180(1.2 \%)$ & $1948(100.0 \%)$ & $16,636(100.0 \%)$ \\
\hline
\end{tabular}

Fig. 3 Distribution of hypertension status in surveyed population

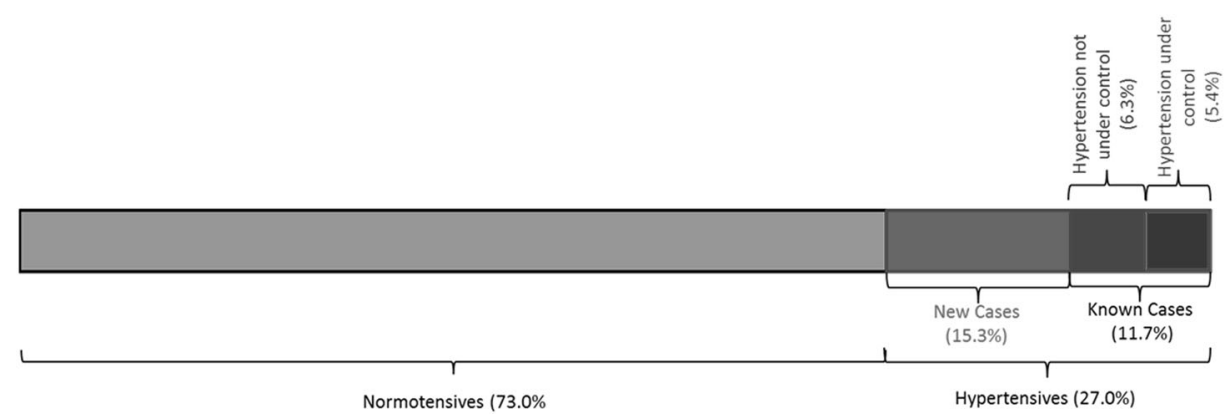

the individuals above 60 years of age were normotensive. The trend of increasing stages of hypertension with age was found to be statistically significant (Kendall's tau correlation coefficient $0.284, p$-value $<0.000$ ). Odds of hypertension $(\mathrm{BP} \geq 140 / 90)$ increased by $5 \%$ for every one year increase in age of individuals and it was statistically significant (OR 1.05; 95\% CI: $1.04-1.05$, $p$-value $<0.001)$. Odds of hypertension ( $\mathrm{BP} \geq 140 / 90)$ were 2.82 times higher in subjects aged between 25-40 years as compared to base category of $<25$ years and it was statistically significant (OR 2.82; $95 \%$ CI: 2.24-3.56, $p$-value $<0.001)$. In addition, subjects aged between 40-60 years also had more than seven times higher odds of hypertension (BP $>=140 / 90$ ) as compared to subjects below 25 years of age (OR 7.68; 95\% CI: 6.17-9.56; $p$ value $<0.001)$. Similarly, odds of hypertension were more than 15 times higher in elderly subjects aged $>60$ years in comparison to base category of subjects aged below 25 years and it was again statistically significant (OR 15.67;95\% CI: 12.60-19.49, $p$-value $<0.001)$.

A short survey done for consanguinity in a subset of the population revealed that out of the 3319 married individuals, 631 (19.0\%) had consanguineous marriages. Among them 206 (32.6\%) individuals were married with their cousins from paternal family, $319(50.6 \%)$ were married with their cousins from maternal family and 106 (16.8\%) were married with their sister's daughter. Out of 3660 surveyed individuals, only 3058 were aware of their parents' marriage within their family. Among them, 174 (5.7\%) individuals parents had consanguineous unions; 45 (25.9\%)

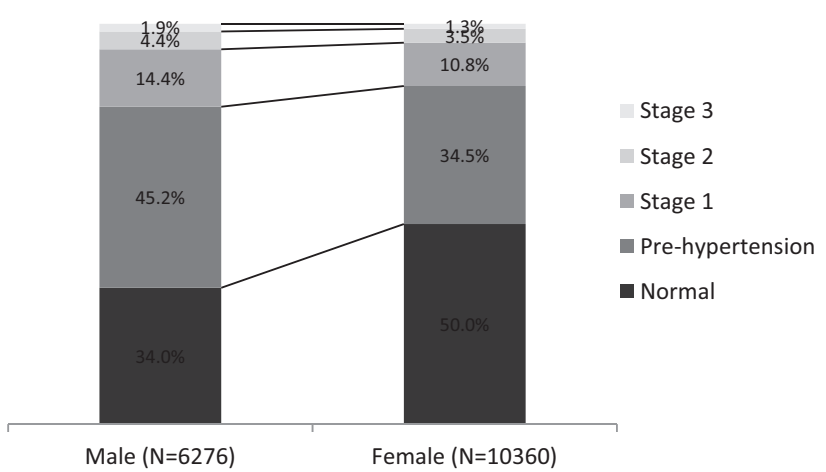

Fig. 4 Distribution of blood pressure measurements among males and females in study population (age-adjusted as per WHO standard population and normalized)

being married with their cousins from maternal side, 80 (46\%) married with cousins from maternal side and 49 $(28.2 \%)$ married with their sister's daughter. Other socioeconomic and personal predictors were also analyzed for their association with hypertension.

\section{Risk factors}

The risk factors that were investigated in this study included age, gender, physical activity, smoking, alcohol, educational status, income, occupation, BMI, weight quartile, waist-hip ratio, cooking oil used, blood sugar level and the family history of hypertension and diabetes. Univariate and 
Table 3 Average age of individuals with various stages of hypertension

\begin{tabular}{|c|c|c|c|c|c|}
\hline \multirow[t]{2}{*}{ Stage } & \multicolumn{2}{|l|}{ Females } & \multicolumn{2}{|l|}{ Males } & \multirow{2}{*}{$\frac{\text { Both sexes }}{\text { Mean age }( \pm S D) \text { in years }}$} \\
\hline & $N(\%)$ & Mean age $( \pm$ SD $)$ in years & $N$ & Mean age $( \pm S D)$ in years & \\
\hline Normal & $4639(44.8 \%)$ & $38( \pm 16)$ & $1894(30.2 \%)$ & $43( \pm 19)$ & $39( \pm 17)$ \\
\hline Prehypertension & $3731(36.0 \%)$ & $46( \pm 17)$ & $2778(44.3 \%)$ & $46( \pm 17)$ & $46( \pm 17)$ \\
\hline Stage 1 HTN & $1371(13.2 \%)$ & $56( \pm 15)$ & $1057(16.8 \%)$ & $54( \pm 17)$ & $55( \pm 16)$ \\
\hline Stage 2 HTN & $451(4.4 \%)$ & $59( \pm 14)$ & $382(6.1 \%)$ & $59( \pm 14)$ & $59( \pm 14)$ \\
\hline Stage $3 \mathrm{HTN}$ & $168(1.6 \%)$ & $60( \pm 15)$ & $165(2.6 \%)$ & $59( \pm 15)$ & $60( \pm 14)$ \\
\hline Grand total & $10,360(100 \%)$ & $45( \pm 17)$ & $6276(100 \%)$ & $47( \pm 18)$ & $46( \pm 18)$ \\
\hline
\end{tabular}

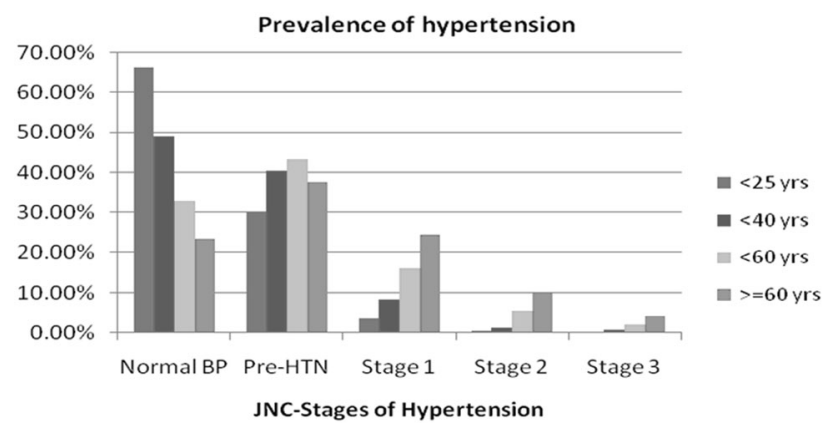

Fig. 5 Prevalence of hypertension in different age groups

multivariate logistic regression analysis was done to estimate adjusted odds ratio for outcome of hypertension based on these predictors. The results are shown in Table 4.

\section{Univariate analysis}

Odds of hypertension were significantly increased among current smokers and those who consumed alcohol (OR 1.61; 95\% CI: $1.42-1.82 ; p$-value $<0.001$ and OR 1.43 ; 95\% CI: $1.26-1.62 ; p$-value $<0.001$, respectively). However, tobacco chewing or level of exercise did not have any statistically significant impact on odds of developing hypertension (OR 1.03; $p$-value 0.41 and OR $1.14 ; p$-value 0.34 , respectively).

The users of Palm oil, which is being issued under the State Public Distribution System (PDS) since 2013; were found to have lower odds of developing hypertension by nearly $30 \%$ (OR $0.71 ; 95 \%$ CI: $0.74-0.89$ ) as compared to sunflower oil users $(p$-value $<0.001)$. Also users of ground nut oil, mostly extracted from the locally grown crop, had nearly $20 \%$ lower odds of developing hypertension (OR 0.81 ; $95 \%$ CI: $0.74-0.89$ ) as compared to sunflower oil users $(p$-value $<0.001)$.

\section{Multivariate analysis}

Overall effect of multivariate logistic regression model was computed as McFadden's pseudo $\mathrm{R}$ square, which was
$14.6 \%$ (i.e. explaining $14.6 \%$ of outcome variability) and model as a whole was also statistically significant (LR Chi square test: $3235 ; p$-value $<0.0001)$. Interaction among independent variables particularly age, BMI, gender and body weight quartiles was checked. The results with all these interaction terms in the model were similar to the original regression model except that predictor BMI failed to retain its statistical significance. Since, it is clinically well established that BMI has independent predictive value for outcome of hypertension, it was retained in the initial model with ten predictors having independent prognostic role for the outcome of hypertension. Gender, diabetes and age retained their significance as risk factors for hypertension. Further, increased BMI, waist-hip ratio, and body weight were found to be independent risk factors for hypertension as also family history of hypertension and death of spouse. Interestingly, lower income, illiteracy and farming emerged as protection against hypertension in the surveyed community. Habit of smoking and alcohol intake lost their independent predictive ability for hypertension. The type of oil used for cooking also lost independent predictive ability on multivariate analysis.

\section{Discussion}

Overall prevalence of hypertension in the surveyed rural population has been found to be almost equal to what has been estimated by recent studies in developing countries like Vietnam $(25.1 \%)[16,17]$ and also as per meta-analysis of Indian studies which found overall prevalence for hypertension in India as $29.8 \%$ (95\% CI, 26.7, 33.0), with a prevalence of $27.6 \%(23.2,32.0)$ in rural areas, however, our study estimate was higher than that of rural south India $(21.1 \%, 20.1,22.0)$ [9]. Our study thus shows an increasing prevalence in rural South India. This prevalence would be even higher if standardized for gender distribution since more than $62 \%$ of surveyed population was females as against $50.3 \%$ of females in Thavanampalle Mandal per 2011 census. Most risk factors identified with multivariate analysis were consistent with known risk factors found in 
Table 4 Univariate and multivariate logistic regression analysis for identifying risk factors for hypertension in study population

\begin{tabular}{|c|c|c|c|c|c|c|}
\hline \multirow[t]{2}{*}{ Risk factor } & & \multirow[t]{2}{*}{$N$} & \multicolumn{2}{|c|}{ Univariate logistic regression } & \multicolumn{2}{|c|}{ Multivariate logistic regression } \\
\hline & & & Odds ratio $(95 \% \mathrm{CI})$ & $z(p$-value $)$ & Odds ratio $(95 \% \mathrm{CI})$ & $t(p$-value $)$ \\
\hline \multirow[t]{2}{*}{ Gender } & Male & $6276(37.7 \%)$ & 1 (base) & - & 1 (base) & - \\
\hline & Female & $10,360(62.3 \%)$ & $0.53(0.50-0.57)$ & $-18.58(<0.001)$ & $0.56(0.50-0.64)$ & $-8.81(<0.001)$ \\
\hline \multirow[t]{4}{*}{ Age } & $<25$ years & $2326(14.0 \%)$ & 1 (base) & - & 1 (base) & - \\
\hline & $25-40$ years & $4295(25.8 \%)$ & $2.82(2.24-3.56)$ & $8.79(<0.001)$ & $1.56(1.36-1.78)$ & $6.58(<0.001)$ \\
\hline & $40-60$ years & $5558(33.4 \%)$ & $7.68(6.17-9.55)$ & $18.29(<0.001)$ & $3.02(2.61-3.48)$ & $15.06(<0.001)$ \\
\hline & $>60$ years & $4457(26.8 \%)$ & $15.67(12.60-19.49)$ & $24.73(<0.001)$ & $5.47(4.67-6.41)$ & $20.97(<0.001)$ \\
\hline \multirow[t]{4}{*}{ Education } & $>=$ Graduate & $1804(10.8 \%)$ & 1 (base) & - & 1 (base) & - \\
\hline & $\mathrm{ITI} / \mathrm{Sr} \mathrm{Sec}$ & $1965(11.8 \%)$ & $0.68(0.58-0.82)$ & $-4.23(<0.001)$ & $0.81(0.70-0.95)$ & $-2.64(<0.01)$ \\
\hline & $\begin{array}{l}\text { Primary-middle } \\
\text { school }\end{array}$ & $6813(41.0 \%)$ & $1.23(1.08-1.40)$ & $3.14(<0.002)$ & $0.89(0.78-1.03)$ & $-1.61(0.11)$ \\
\hline & Illiterate & $6054(36.4 \%)$ & $1.34(1.17-1.52)$ & $4.36(<0.001)$ & $0.81(0.69-0.95)$ & $-2.63(<0.01)$ \\
\hline \multirow[t]{4}{*}{ Marital status } & Unmarried & $2053(12.3 \%)$ & 1 (base) & - & 1 (base) & - \\
\hline & Married & $12,671(76.2 \%)$ & $2.85(2.43-3.34)$ & $13.02(<0.001)$ & $1.08(0.94-1.25)$ & $1.12(0.26)$ \\
\hline & Separated/divorced & $99(0.6 \%)$ & $3.66(2.28-5.87)$ & $5.38(<0.001)$ & $1.05(0.66-1.65)$ & $0.20(0.84)$ \\
\hline & Widow(er) & $1813(10.9 \%)$ & $5.50(4.59-6.59)$ & $18.54(<0.001)$ & $1.59(1.31-1.92)$ & $4.79(<0.001)$ \\
\hline \multirow[t]{5}{*}{ Employment status } & Unemployed & $3554(21.4 \%)$ & 1 (base) & - & 1 (base) & - \\
\hline & $\begin{array}{l}\text { Employee/ } \\
\text { shopkeeper }\end{array}$ & $779(4.7 \%)$ & $1.23(1.03-1.48)$ & $2.24(0.025)$ & $0.89(0.71-1.10)$ & $-1.08(0.28)$ \\
\hline & Farmer & $3210(19.3 \%)$ & $1.30(1.16-1.46)$ & $4.60(<0.001)$ & $0.68(0.58-0.79)$ & $-4.90(<0.001)$ \\
\hline & Worker & $1314(7.9 \%)$ & $1.15(0.99-1.34)$ & $1.87(0.061)$ & $0.89(0.75-1.06)$ & $-1.28(0.20)$ \\
\hline & Homemaker & $7779(46.8 \%)$ & $0.93(0.84-1.02)$ & $-1.46(0.144)$ & $0.92(0.82-1.03)$ & $-1.40(0.16)$ \\
\hline \multirow[t]{5}{*}{ Income per month (Rs) } & $\geq 11,400$ & $399(2.4 \%)$ & 1 (base) & - & 1 (base) & - \\
\hline & $7600-11,400$ & $323(1.9 \%)$ & $1.09(0.79-1.51)$ & $0.55(0.58)$ & $0.91(0.62-1.34)$ & $-0.48(0.63)$ \\
\hline & $4500-7600$ & $1186(7.1 \%)$ & $0.92(0.72-1.18)$ & $-0.64(0.52)$ & $0.75(0.56-1.00)$ & $-1.95(<0.05)$ \\
\hline & $1500-4500$ & $2672(16.1 \%)$ & $0.68(0.54-0.86)$ & $-3.21(0.001)$ & $0.63(0.48-0.82)$ & $-3.43(<0.001)$ \\
\hline & $<1500$ & $12,056(72.5 \%)$ & $0.63(0.50-0.78)$ & $-4.13(<0.001)$ & $0.71(0.55-0.92)$ & $-2.61(<0.01)$ \\
\hline \multirow{2}{*}{$\begin{array}{l}\text { Random blood glucose } \\
(\mathrm{mg} / \mathrm{dl})\end{array}$} & $<200$ & $15,488(93.1 \%)$ & 1 (base) & - & 1 (base) & - \\
\hline & $\geq 200$ & $1148(6.9 \%)$ & $3.67(3.25-4.15)$ & $20.83(<0.001)$ & $1.96(1.63-2.35)$ & $7.25(<0.001)$ \\
\hline \multirow[t]{4}{*}{ Body mass index $\left(\mathrm{kg} / \mathrm{m}^{2}\right)$} & $<18.5$ & $2911(17.5 \%)$ & 1 (base) & - & 1 (base) & - \\
\hline & $18.5-25$ & $8862(53.3 \%)$ & $2.19(1.92-2.50)$ & $11.75(<0.001)$ & $1.47(1.32-1.65)$ & $6.78(<0.001)$ \\
\hline & $25-30$ & $3511(21.1 \%)$ & $3.81(3.31-4.38)$ & $18.71(<0.001)$ & $1.73(1.47-2.04)$ & $6.61(<0.001)$ \\
\hline & $>30$ & $1310(7.9 \%)$ & $4.93(4.18-5.81)$ & $18.95(<0.001)$ & $2.05(1.63-2.58)$ & $6.17(<0.001)$ \\
\hline \multirow[t]{2}{*}{ Waist-hip ${ }^{a}$ ratio } & Normal & $5856(35.2 \%)$ & 1 (base) & - & 1 (base) & - \\
\hline & Increased & $10,780(64.8 \%)$ & $1.56(1.44-1.70)$ & $10.80(<0.001)$ & $1.20(1.11-1.29)$ & $4.52(<0.001)$ \\
\hline \multirow[t]{4}{*}{ Body weight (kg) } & 1st quartile $(\leq 46)$ & $4350(26.1 \%)$ & 1 (base) & - & 1 (base) & - \\
\hline & $\begin{array}{l}\text { 2nd quartile } \\
(47-55)\end{array}$ & $4718(28.4 \%)$ & $1.38(1.23-1.55)$ & $5.39(<0.001)$ & $1.55(1.39-1.72)$ & $8.10(<0.001)$ \\
\hline & 3rd quartile (56-65) & $4057(24.4 \%)$ & $2.27(2.03-2.54)$ & $14.21(<0.001)$ & $2.38(2.09-2.71)$ & $13.08(<0.001)$ \\
\hline & 4th quartile $(>65)$ & $3492(21.0 \%)$ & $3.44(3.07-3.85)$ & $21.50(<0.001)$ & $3.31(2.77-3.94)$ & $13.29(<0.001)$ \\
\hline \multirow[t]{3}{*}{ Oil used in cooking } & Sunflower oil & $2589(15.6 \%)$ & 1 (base) & - & 1 (base) & - \\
\hline & Palm oil & $4405(26.5 \%)$ & $0.71(0.65-0.79)$ & $-6.53(<0.001)$ & $1.08(0.96-1.22)$ & $1.32(0.19)$ \\
\hline & Ground nut oil & $9606(57.7 \%)$ & $0.81(0.74-0.89)$ & $-4.54(<0.001)$ & $1.03(0.93-1.15)$ & $0.60(0.55)$ \\
\hline \multirow[t]{2}{*}{ Smoking } & No & $15,246(91.6 \%)$ & 1(Base) & - & 1 (base) & - \\
\hline & Yes & $1390(8.4 \%)$ & $1.61(1.42-1.82)$ & $7.33(<0.001)$ & $0.92(0.78-1.10)$ & $-0.92(0.36)$ \\
\hline \multirow[t]{2}{*}{ Alcohol consumption } & No & $15,265(91.8 \%)$ & 1 (base) & - & 1 (base) & - \\
\hline & Yes & $1371(8.2 \%)$ & $1.43(1.26-1.62)$ & $5.65(<0.001)$ & $1.15(0.97-1.36)$ & $1.59(0.11)$ \\
\hline
\end{tabular}


Table 4 (continued)

\begin{tabular}{|c|c|c|c|c|c|c|}
\hline \multirow[t]{2}{*}{ Risk factor } & & \multirow[t]{2}{*}{$N$} & \multicolumn{2}{|c|}{ Univariate logistic regression } & \multicolumn{2}{|c|}{ Multivariate logistic regression } \\
\hline & & & Odds ratio $(95 \% \mathrm{CI})$ & $z$ (p-value) & Odds ratio $(95 \% \mathrm{CI})$ & $t$ (p-value) \\
\hline \multirow{2}{*}{$\begin{array}{l}\text { Family history of } \\
\text { hypertension }\end{array}$} & No & $15,346(92.2 \%)$ & - & - & 1 (base) & - \\
\hline & Yes & $1290(7.8 \%)$ & $2.72(2.42-3.07)$ & $16.66(<0.001)$ & $1.69(1.43-2.01)$ & $6.15(<0.001)$ \\
\hline \multirow{2}{*}{$\begin{array}{l}\text { Family history of } \\
\text { diabetes }\end{array}$} & No & $15,496(93.1 \%)$ & - & - & 1 (base) & - \\
\hline & Yes & $1140(6.9 \%)$ & $2.02(1.78-2.21)$ & $10.76(<0.001)$ & $1.15(0.96-1.38)$ & $1.52(0.13)$ \\
\hline
\end{tabular}

Bold values show that the level of significance was high since $p$ value was less than 0.05 . These values indicate important risk factors out of the entire list in table

${ }^{a}$ Waist hip ratio: Normal was labeled for ratio $<0.85$ for females and $<0.95$ for males, respectively, Increased was labeled for ratio $\geq 0.85$ for females and $\geq 0.95$ for males

surveys elsewhere except for the risk lowering factors of low-income and illiteracy. Lower prevalence of hypertension among farmers is consistent with similar findings in a study in Vietnam [17]. Higher risk of hypertension among widow(er)s in the surveyed population is also consistent with known association of worse health outcomes among them [18].

Our study estimates of $32.5 \%$, being aware of their hypertensive status, was marginally higher than that estimated in a meta-analysis (25.3\%) [9]. The present study showed that $46.2 \%$ of subjects who were aware of their hypertensive state and on management had satisfactory control of their BP, which is higher than that found in a study among a multinational population, where only $32.5 \%$ of individuals aware of their diagnosis and receiving pharmacological treatment had adequate control of their BP [19]. However, our study estimates were higher than other Indian studies which showed $25.1 \%(17.0-33.1)$, and $10.7 \%$ (6.5-15.0) with adequate treatment and control, respectively, in rural India [9].

An early decline in diastolic BP among the males in the surveyed population is an important finding to corroborate a well-accepted notion that cardiovascular events occur at least a decade earlier in Indian population. Such a finding is essential to set guidelines for hypertension treatment in local population. Although the J-curve phenomenon remains controversial [20], it still remains an important concept to investigate especially when there is an intent to intervene, in a community with high prevalence of diabetes, to reduce risks of hypertension with anti-hypertensives and lifestyle modifications.

The demonstrated association of hypertension with age, gender, BMI, waist-hip ratio, body weight, family history of hypertension, and diabetes is almost similar but not in complete consonance with the findings of other Indian studies. BMI and central obesity (waist -hip ratio) have been found to be associated with hypertension in a large number of Indian studies [9]. However, as compared to other Indian studies, alcohol and smoking lost independent predictive ability in multivariate analysis in current study [9].

The high prevalence of hypertension in the study area and its association with the risk factors mandate that management for hypertension, as for other non-communicable chronic diseases (NCD), be implemented from the perspective of predictive, preventive and personalized medicine (PPPM) and not after disease onset, which would be a delayed approach [21-23]. The growing NCD pandemic will increase the economic burden for healthcare system in an already resource constrained community. As hypertension is easily diagnosable and treatable, its control could be utilized as an initiator to prevent and control other NCDs. High impact, sustainable and cost effective populationbased prevention strategies utilizing multi-sectoral approach for targeting lifestyle change are required to be implemented. This coupled with public policies, regulatory, and consumer education approaches, including increasing physical activity have been shown to prevent further increase with impact on other NCDs. Outcomes of such populationbased PPPM interventions need to be studied to develop guidelines for the most-effective prevention module in the local population before implementation at the national level.

\section{Strengths and limitations of the study}

The current study has brought out the magnitude and association of genetic and environmental factors with hypertension. However, as only limited investigations were done and as the impact of important dietary risk factors such as salt, vegetables, and fruit intake as also the role of stress could not be fully covered, these remain as major limitations of the study. However, these will be included during the prospective follow up of the study population. Further, any causal association of the variables with hypertension cannot be derived from the current cross-sectional study. 
The strength of this study is that these participants will be followed up in a prospective manner and causal association of the variables and also the effectiveness of preventive strategies undertaken to control them can be studied.

What is known about topic?

- Rising prevalence of hypertension in rural India.

- Multiple risk factors, both modifiable and non-modifiable. Significant among them being, age, sex, ethnicity, family history, obesity, not being physically active, use of tobacco, alcohol, diet related including too much salt or too little potassium or Vitamin D, Stress, and certain chronic conditions such as kidney disease, diabetes, and sleep apnea.

What this study adds?

- Actual prevalence of hypertension in the area of survey and effect of control measures being adopted.

- Demonstration of decline in diastolic blood pressure among males in fifth decade of life which is 15 years earlier than the documented data from the Western world. This is likely to result in a revised strategy for hypertension management especially in individuals with myocardial infarction in view of the J-curve phenomenon.

- Effect of risk factors including illiteracy, poverty, physical activity, consumption of alcohol, and consumption of palm oil have been reported differently in the study than in earlier studies.

- Identification of hypertensives including those previously diagnosed and on inappropriate management and putting them on a structured protocol with continuous monitoring.

- The current cross-sectional study of the population has thus identified the individuals with hypertension and other noncommunicable diseases as well as those at high risk of these diseases in the community and has provided a large cohort, which is now being followed up through the clinics established in the study location to understand comprehensively the impact of risk factors on the disease process and their control. It has thereby provided a platform for implementation and evaluation of population based interventional strategies in a semi-rural population which comprises a large subsection of the Indian population in a transitional stage of evolution from a rural to an urban society.

\section{Compliance with ethical standards}

Conflict of interest The authors declare that they have NO affiliations with or involvement in any organization or entity with any financial interest (such as honoraria; educational grants; participation in speakers' bureaus; membership, employment, consultancies, stock ownership, or other equity interest; and expert testimony or patentlicensing arrangements), or non-financial interest (such as personal or professional relationships, affiliations, knowledge, or beliefs) in the subject matter or materials discussed in this manuscript.

Open Access This article is licensed under a Creative Commons Attribution-NonCommercial-ShareAlike 4.0 International License, which permits any non-commercial use, sharing, adaptation, distribution and reproduction in any medium or format, as long as you give appropriate credit to the original author(s) and the source, provide a link to the Creative Commons license, and indicate if changes were made. If you remix, transform, or build upon this article or a part thereof, you must distribute your contributions under the same license as the original. The images or other third party material in this article are included in the article's Creative Commons license, unless indicated otherwise in a credit line to the material. If material is not included in the article's Creative Commons license and your intended use is not permitted by statutory regulation or exceeds the permitted use, you will need to obtain permission directly from the copyright holder. To view a copy of this license, http://creativecommons.org/ licenses/by-nc-sa/4.0/.

\section{References}

1. Ibrahim MM, Damasceno A. Hypertension in developing countries. Lancet (London, England). 2012;380:611-9.

2. Lackland DT, Ram CVS. World Hypertension League: its scope, purpose, and impact in South Asia. Hypertens J. 2016;2:55-6.

3. Gupta R. Trends in hypertension epidemiology in India. J Hum Hypertens. 2004;18:73-8.

4. Kearney PM, Whelton M, Reynolds K, Muntner P, Whelton PK, He J. Global burden of hypertension. Analysis of worldwide data. Lancet (London, England). 2005;365:217-23.

5. Campbell NR, Lackland DT, Lisheng L, Zhang XH, Nilsson PM, Redburn KA, et al. The World Hypertension League challenges hypertension and cardiovascular organizations to develop strategic plans for the prevention and control of hypertension. J Clin Hypertens (Greenwich). 2015;17:325-7

6. Banach M, Aronow WS. Blood pressure j-curve current concepts. Curr Hypertens Rep. 2012;14:556-66.

7. Franklin SS, Gustin W,4th, Wong ND, Larson MG, Weber MA, Kannel WB, et al. Hemodynamic patterns of age-related changes in blood pressure. The Framingham Heart Study. Circulation. 1997;96:308-15

8. Basu S, Millett C. Social epidemiology of hypertension in middleincome countries. Determinants of prevalence, diagnosis, treatment, and control in the WHO SAGE study. Hypertension (Dallas, Tex.: 1979). 2013;62:18-26.

9. Anchala R, Kannuri NK, Pant H, Khan H, Franco OH, Di Angelantonio E, et al. Hypertension in India. A systematic review and meta-analysis of prevalence, awareness, and control of hypertension. J Hypertens. 2014;32:1170-7

10. McNaughton CD, Jacobson TA, Kripalani S. Low literacy is associated with uncontrolled blood pressure in primary care patients with hypertension and heart disease. Patient Educ Couns. 2014;96:165-70.

11. Gupta R, Gupta VP, Ahluwalia NS, Educational status, coronary heart disease, and coronary risk factor prevalence in a rural population ofIndia. BMJ (Clinical researched.). 1994;309:1332-6

12. Gupta R, Deedwania PC, Achari V, Bhansali A, Gupta BK, Gupta $\mathrm{A}$, et al. Normotension, prehypertension, and hypertension in urban middle-class subjects in India. Prevalence, awareness, treatment, and control. Am J Hypertens. 2013;26:83-94.

13. Rudan I, Smolej-Narancic N, Campbell H, Carothers A, Wright A, Janicijevic B, et al. Inbreeding and the genetic complexity of human hypertension. Genetics. 2003;163:1011-21

14. Bittles AH, Savithri HS, Venkatesha Murthy HS, Baskaran G, Wang W, Cahill J, \& Appaji Rao, N. Human inbreeding, a familiar story full of surprises. In: Macbeth H, Shetty P editors. Health and Ethnicity, 68-78. London, Taylor \& Francis, 2001.

15. Weber MA, Lackland DT. Contributions to hypertension public policy and clinical practice. A review of recent reports. J Clin Hypertens (Greenwich). 2016;18:1063-70.

16. Son PT, Quang NN, Viet NL, Khai PG, Wall S, Weinehall L, et al. Prevalence, awareness, treatment and control of hypertension in Vietnam-results from a national survey. J Hum Hypertens. 2012;26:268-80 
17. van Minh H, Byass P, Chuc NTK, Wall S. Gender differences in prevalence and socioeconomic determinants of hypertension. Findings from the WHO STEPs survey in a rural community of Vietnam. J Hum Hypertens. 2006;20:109-15.

18. Perkins JM, Lee HY, James KS, Oh J, Krishna A, Heo J, et al. Marital status, widowhood duration, gender and health outcomes. A cross-sectional study among older adults in India. BMC Public Health. 2016;16:1032

19. Chow CK, Teo KK, Rangarajan S, Islam S, Gupta R, Avezum A, et al. Prevalence, awareness, treatment, and control of hypertension in rural and urban communities in high-, middle-, and lowincome countries. JAMA. 2013;310:959-68

20. Bangalore S, Messerli FH, Wun CC, Zuckerman AL, DeMicco D, Kostis JB, et al. J-curve revisited. An analysis of blood pressure and cardiovascular events in the Treating to New Targets (TNT) Trial. Eur Heart J. 2010;31:2897-08

21. Golubnitschaja O, Costigliola V. European strategies in predictive, preventive and personalised medicine. Highlights of the EPMA World Congress 2011. EPMA J. 2011;2:315-32.

22. Wang W, Russell A, Yan Y. Traditional Chinese medicine and new concepts of predictive, preventive and personalized medicine in diagnosis and treatment of suboptimal health. EPMA J. 2014;5:4.

23. Bodrova TA, Kostyushev DS, Antonova EN, Slavin S, Gnatenko DA, Bocharova MO, et al. Introduction into PPPM as a new paradigm of public health service. An integrative view. EPMA J. 2012;3:16 